\title{
Self-injury and externalizing pathology: a systematic literature review
}

\author{
Gergely Meszaros ${ }^{1,2^{*}}$ D, Lili Olga Horvath ${ }^{3,4}$ and Judit Balazs²,
}

\begin{abstract}
Background: During the last decade there is a growing scientific interest in nonsuicidal self-injury (NSSI). The aim of the current paper was to review systematically the literature with a special focus on the associations between selfinjurious behaviours and externalizing psychopathology. An additional aim was to review terminology and measurements of self-injurious behaviour and the connection between self-injurious behaviours and suicide in the included publications.

Methods: A systematic literature search was conducted on 31st December 2016 in five databases (PubMed, OVID Medline, OVID PsycINFO, Scopus, Web of Science) with two categories of search terms (1. nonsuicidal self-injury, non-suicidal self-injury, NSSI, self-injurious behaviour, SIB, deliberate self-harm, DSH, self-injury; 2. externalizing disorder, attention deficit hyperactivity disorder, ADHD, conduct disorder, CD, oppositional defiant disorder, OD, ODD).

Results: Finally 35 papers were included. Eleven different terms were found for describing self-injurious behaviours and 20 methods for measuring it. NSSI has the clearest definition. All the examined externalizing psychopathologies had strong associations with self-injurious behaviours according to: higher prevalence rates in externalizing groups than in control groups, higher externalizing scores on the externalizing scales of questionnaires, higher symptom severity in self-injurious groups. Eight studies investigated the relationship between suicide and selfinjurious behaviours and found high overlap between the two phenomena and similar risk factors.
\end{abstract}

Conclusions: Based on the current findings the association between externalizing psychopathology and self-injurious behaviours has been proven by the scientific literature. Similarly to other reviews on self-injurious behaviours the confusion in terminology and methodology was noticed. NSSI is suggested for use as a distinct term. Further studies should investigate the role of comorbid conditions in NSSI, especially when internalizing and externalizing pathologies are both presented.

Keywords: NSSI: nonsuicidal self-injury, DSH: deliberate self-harm, SIB: self-injurious behaviour, self-injury, externalization, ADHD: attention deficit hyperactivity disorder, CD: conduct disorder, ODD: oppositional defiant disorder, psychopathology, psychiatric disorder

\section{Background}

In the past decade self-injury became a hot topic in scientific literature. Nonsuicidal self-injury (NSSI) became an individual diagnosis in the 5th edition of the Diagnostic and Statistical Manual of Mental Disorders [1]; for the present it can be found only in Section III in the

\footnotetext{
* Correspondence: meszaros.gergely.83@gmail.com

'Semmelweis University, Mental Health Sciences School Of Ph.D., Üllói út 26, Budapest 1085, Hungary

${ }^{2}$ Vadaskert Child Psychiatry Hospital and Outpatient Clinic, Lipótmezei út 1-5,

Budapest 1021, Hungary

Full list of author information is available at the end of the article
}

chapter 'Conditions for Further Study'. The definition for NSSI in DSM-5 follows the main instructions of the definition of the 'International Society for the Study of Self-injury' (ISSS), which was made in 2007 [2]. This definition emphasizes the deliberate, nonsuicidal purpose of the self-injurious act, which is not socially sanctioned. It underlines the importance to distinguish it from drug overdoses, culturally sanctioned behaviours (e.g. piercings), and repetitive, stereotypical forms among people with developmental disorders [2]. The DSM-5 suggests as a criterion of NSSI, that self-injurious acts should 
happen on at least 5 days in the past year. Moreover the DSM-5 underlines the non adaptive 'coping strategy' nature of NSSI: the individual who engages in NSSI must have the aim to get to a better emotional state after the action [1].

In the 4th edition of DSM [3], deliberated NSSI can only be found as a symptom of borderline personality disorder (BPD), however clinicians can meet a lot of patients with self-injury without BPD as well. Glenn and Klonsky [4] found in an adolescent psychiatric sample that the coexistence of NSSI and BPD is not more common than the coexistence of any other Axis I diagnoses and NSSI. Zetterqvist [5] found that in the population who met NSSI DSM-5 criteria there are more general psychopathology and impairment, than in the population who did not present NSSI behaviour or in the population who present NSSI behaviour, but did not meet the DSM-5 criteria.

Several risk factors of NSSI are described, such as prior history of NSSI, cluster b personality, hopelessness, female gender, depression, prior suicidal thought/behaviour, exposure to peer NSSI, eating disorder, abuse, etc. [6].

Many studies examined the association between NSSI and internalizing pathology; recently Bentley et al. [7] summarized these studies in their meta-analytic review: all the examined emotional disorders had an increased odds ratio for NSSI, except for bipolar disorder and social anxiety disorder. The association was the strongest with panic and post-traumatic stress disorder, otherwise there were no significant differences between the emotional disorders. Inconsistent methodologies are emphasized, such as the wide range of instruments used to assess NSSI and the multiple terms for self-injury, including NSSI.

The association between externalizing pathology and NSSI are understudied. Although Fox et al. [6] found that the odds ratios of 'misc externalizing symptoms' is higher (1.68) than 'misc internalizing symptoms' (1.37). According to our knowledge, there is only one review that investigated a specific externalizing disorder (attention deficit hyperactivity disorder - ADHD) and its association with self-injury, and found that ADHD is a risk factor of self-harm [8].

Therefore, our aim is to systematically review the studies that examined the association between self-injurious behaviour and externalizing psychopathology. Not only 'NSSI' was chosen as a search word for self-injurious behaviour, because the scientific literature is very confused about the terms [9]. Moreover, e.g. Brunner, Kaess et al. [10] noted this important aspect, often in clinical practice it is hard to distinguish the purpose of a selfinjurious act.

Before investigating the main aim of our study - 1) prevalence rates, odds ratios or other associations between externalizing pathology and self-injury - it seemed to be important to review: 2) terminology and definitions of self-injurious behaviour, and 3) methods for measuring it. Finally, we examined: 4) associations between self-injury and suicide among the included publications.

\section{Methods}

A systematic literature search was made on 31th December 2016 in five computerised literature databases: PubMed, OVID Medline, OVID PsycINFO, Scopus, Web of Science. Search terms were: '(nonsuicidal selfinjury OR non-suicidal self-injury OR NSSI OR selfinjurious behaviour OR SIB OR deliberate self-harm OR DSH or self-injury) AND (externalizing disorder OR attention deficit hyperactivity disorder OR ADHD OR conduct disorder OR CD OR oppositional defiant disorder OR OD OR ODD)'. We found 902 papers in PubMed, 127 papers in OVID Medline, 120 papers in OVID PsycINFO, 116 papers in Web of Science and 16 papers in Scopus, making a total of 1281 studies including duplicates. We used EndNote X7 software for the systematization of the papers. After a duplicate search (both automatic by the software and manual by reading the authors and the titles again) we excluded 222 articles, so altogether we had 1059 individual papers (see the details in Fig. 1).

The flowchart of the inclusion/exclusion process can be seen in Fig. 2. Inclusion criteria were that studies investigating self-injury and externalizing pathology (a), are written in English (b), and reported original data (c). Exclusion criteria were studies: that were not written in English (b), were review/meta-analysis (c), were not about psychiatry/psychology (d), were not about selfinjury (e), were not about externalizing pathology correlation (f).

A QUORUM flowchart of the selection process is summarized in Fig. 1. Publications included in the systematic review were selected in three steps: 1 ) from the 1059 individual papers, based on their titles 767 publications were excluded, 2) from the remaining 292, based on their abstracts 232 more were excluded 3) from the remaining 60 papers, 26 more were excluded after reading their full-texts. Finally, we added 1 paper by manual search. Therefore, a total of 35 papers are included in our systematic review (Table 1). First, each paper's title, abstract and full-text was investigated by the first author, which process was blinded reviewed by the second author. When there was a disagreement between the first and second authors whether a paper should be included or excluded to the systematic review, a common discussion and a final collective decision was made by all the three authors.

The methodology of this systematic descriptive review follows the PRISMA guidelines. 


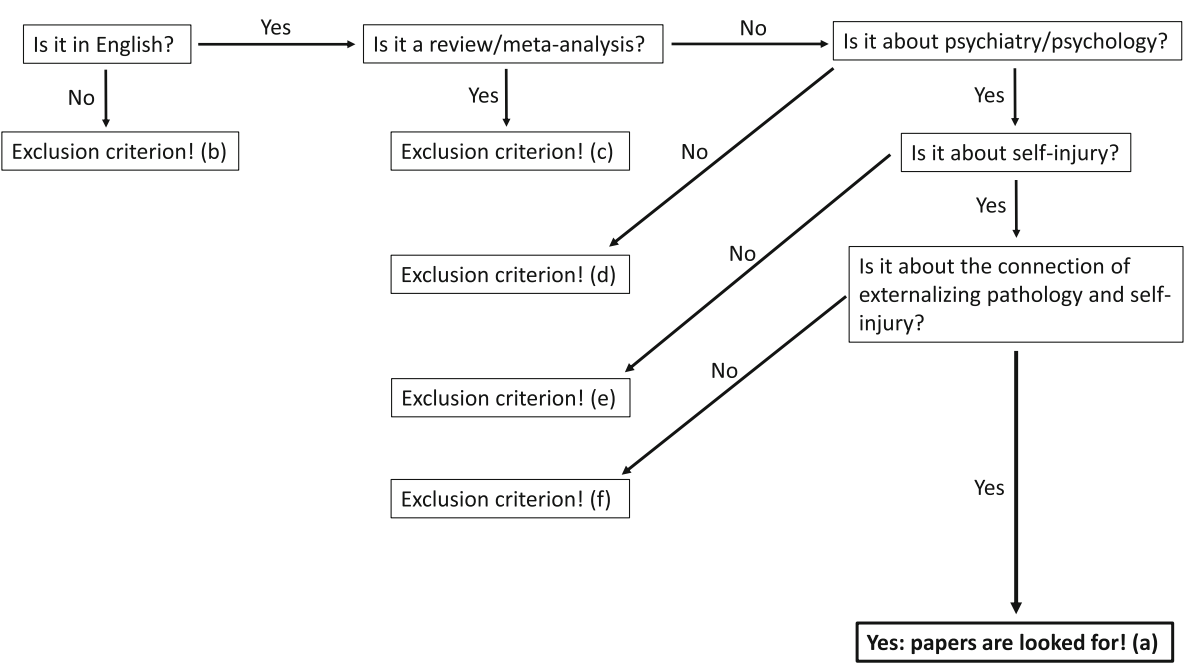

Fig. 1 QUORUM flowchart

\section{Results}

Summary of included papers in the review. Abbreviations: $A D D$ : attention deficit disorder; $A D H D$ : attention deficit hyperactivity disorder; BL: baseline; BPD: borderline personality disorder; CD: conduct disorder; DSH: deliberate self-harm; DSHI: Deliberate Self Harm Inventory; DSP: deliberate self-poisoning; EDR: electrodermal responding; FASM: Functional Assessment of Self-Mutilation; FU: follow-up; IED: intermittent explosive disorder; LPC: Lifetime Parasuicide Count; L-SASI: Lifetime-Suicide Attempt Self-Injury; MDD: major depressive disorder; NSSI: nonsuicidal self-injury; ODD: oppositional defiant disorder; PEP:

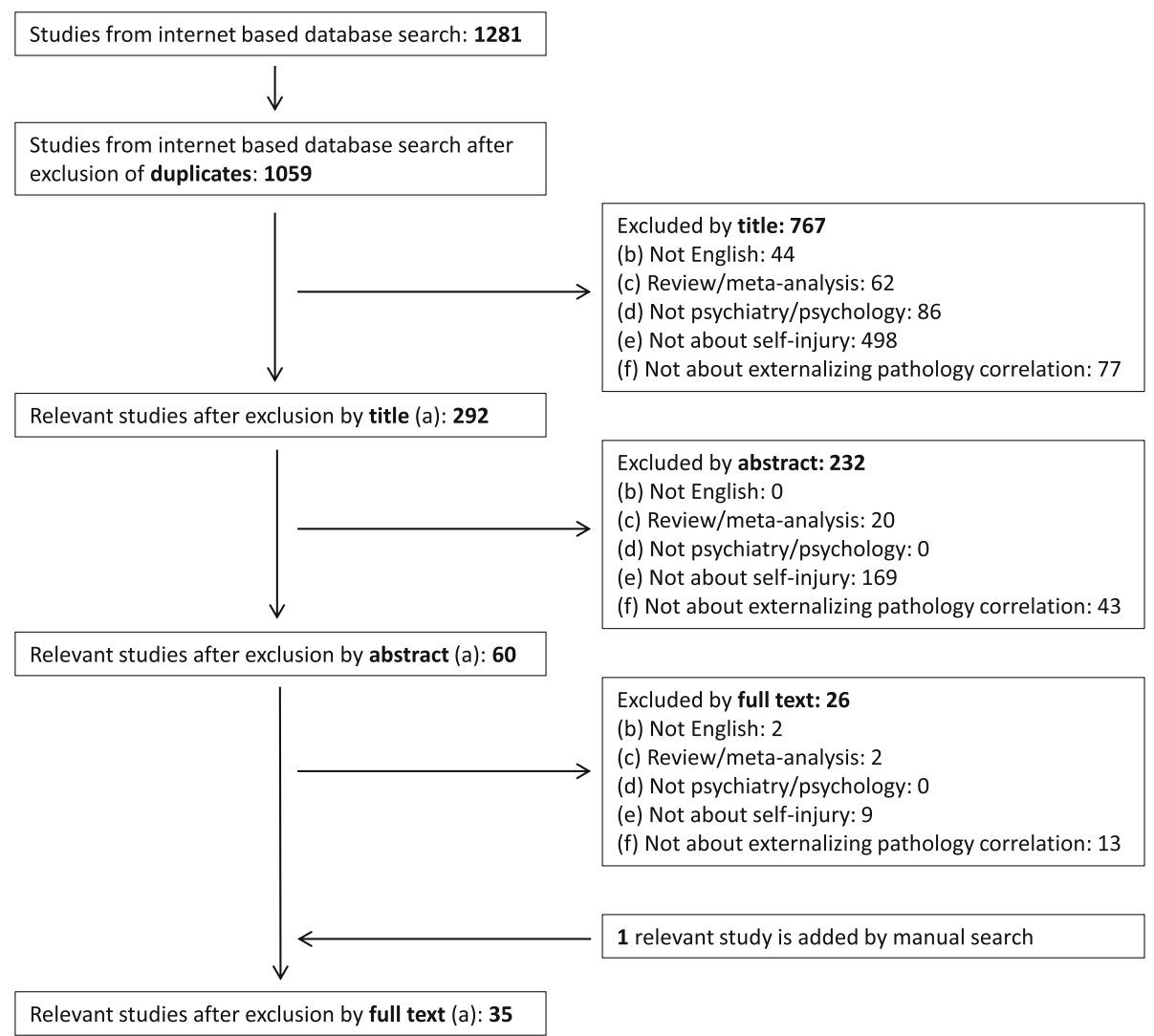

Fig. 2 Flowchart of inclusion/exclusion process 


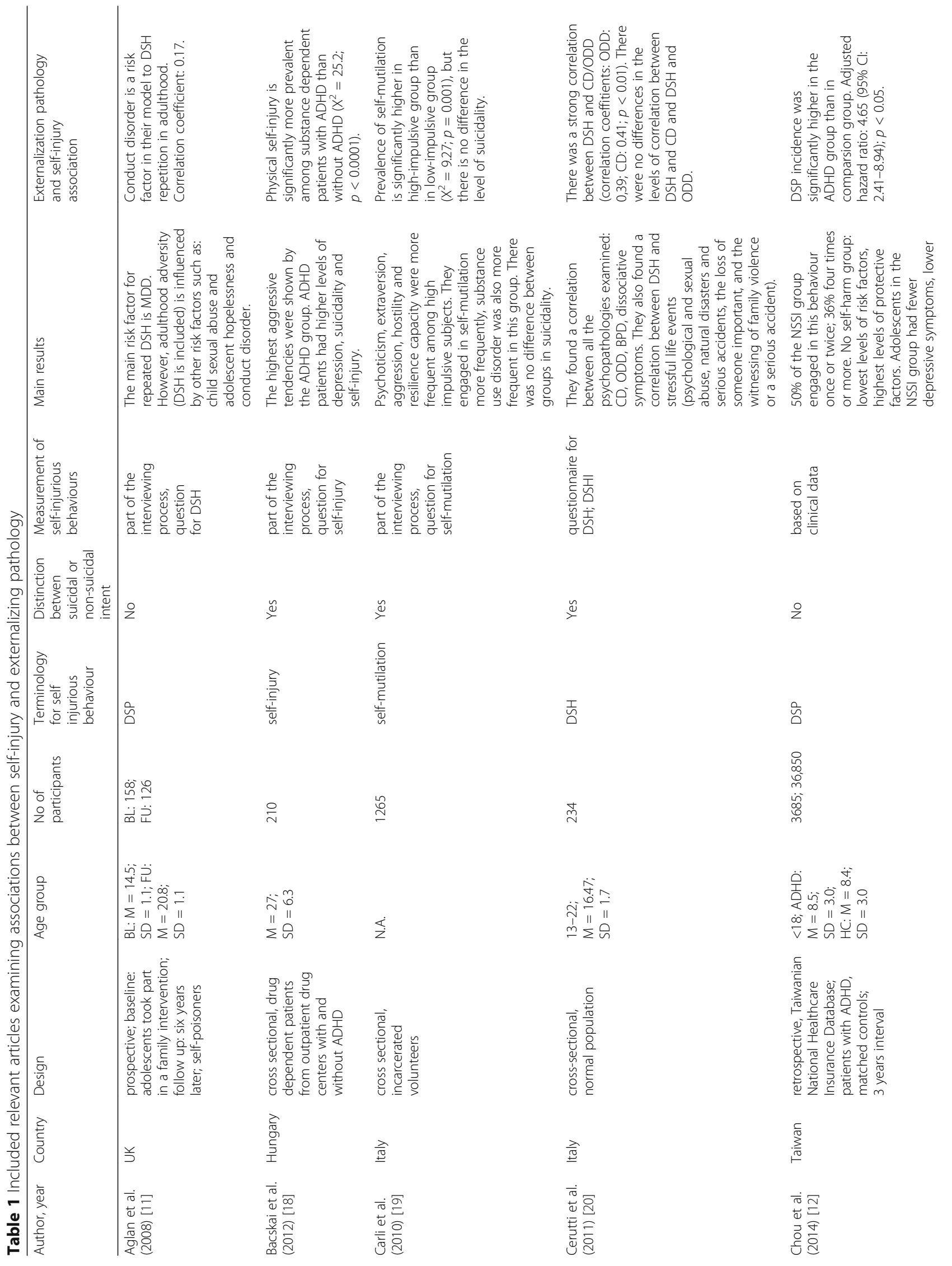




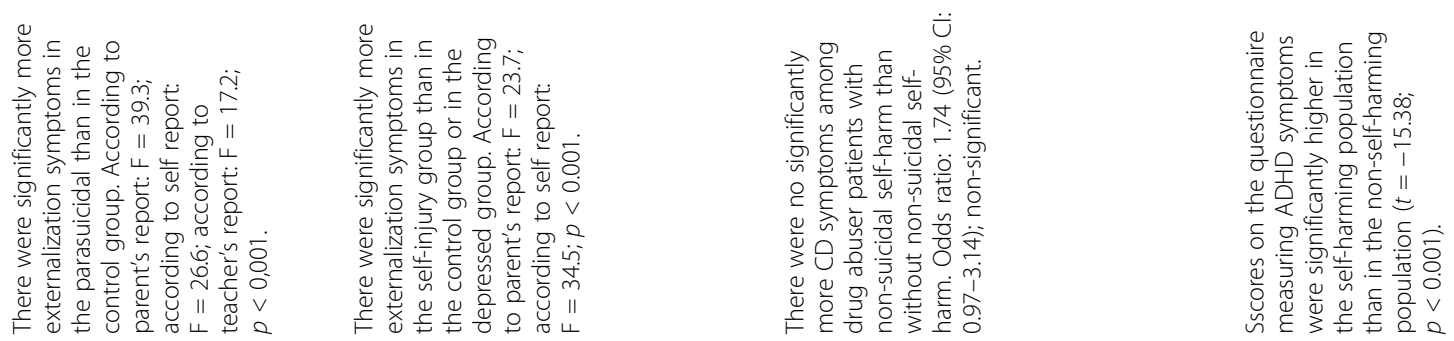

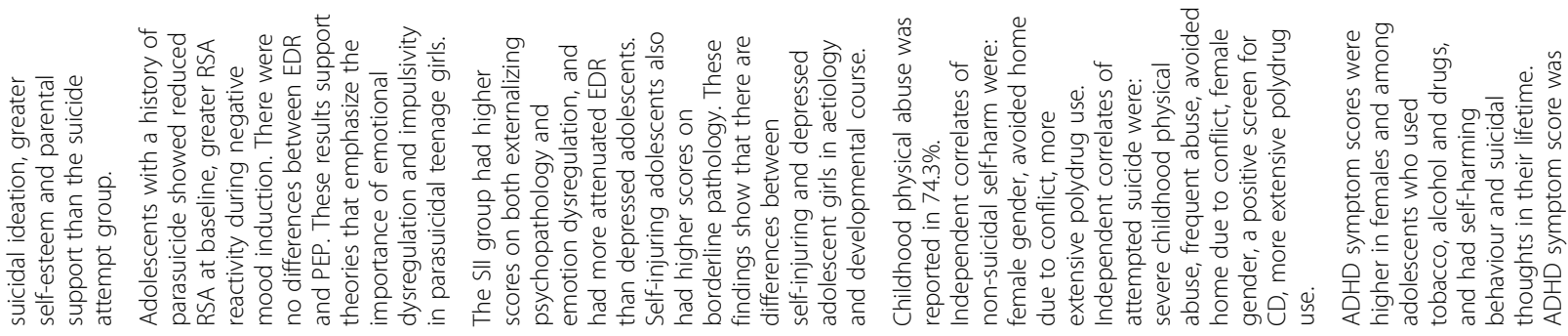

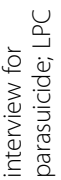

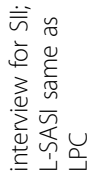

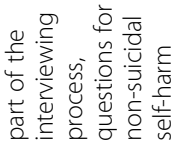

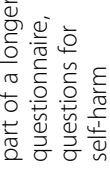

ำ

$\stackrel{\dddot{\nu}}{\searrow}$

$\stackrel{\varpi}{\check{2}}$

$\stackrel{\oiiint}{\check{1}}$

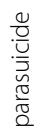

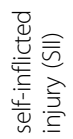

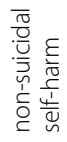

$\underset{\frac{\xi}{0}}{\frac{\xi}{4}}$

๙

令

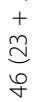

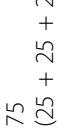

$\stackrel{8}{m}$

$\stackrel{\infty}{\dddot{g}}$

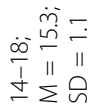

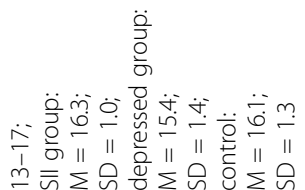

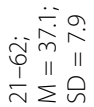

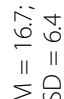

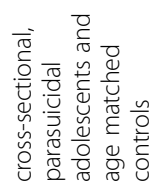

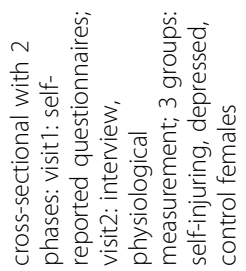

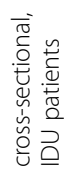

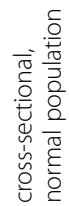

ঙ

芩

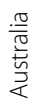

离

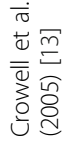

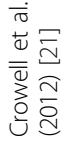

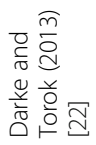

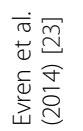



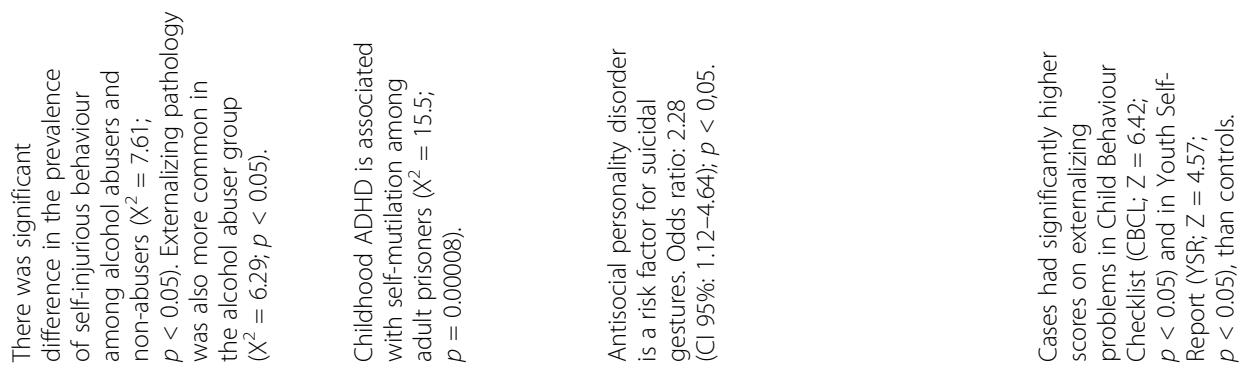

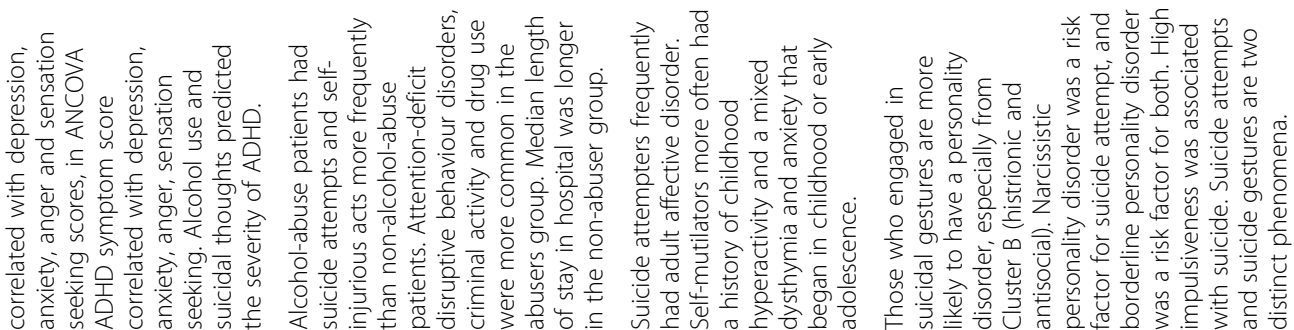

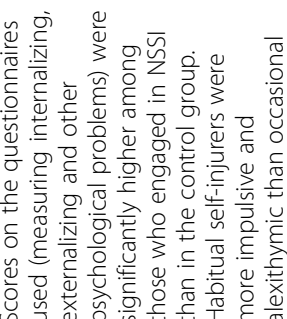

$\stackrel{\Perp}{\searrow}$

$\underset{\substack{\underline{\underline{T}} \\ \frac{3}{4}}}{\frac{3}{4}}$

$\stackrel{\infty}{\sim}$

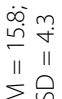

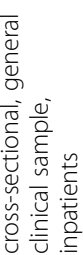

$\overline{\underline{\mathbb{0}}}$

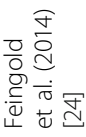

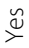

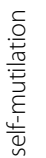

$\bar{m}$

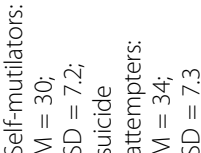

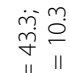

in
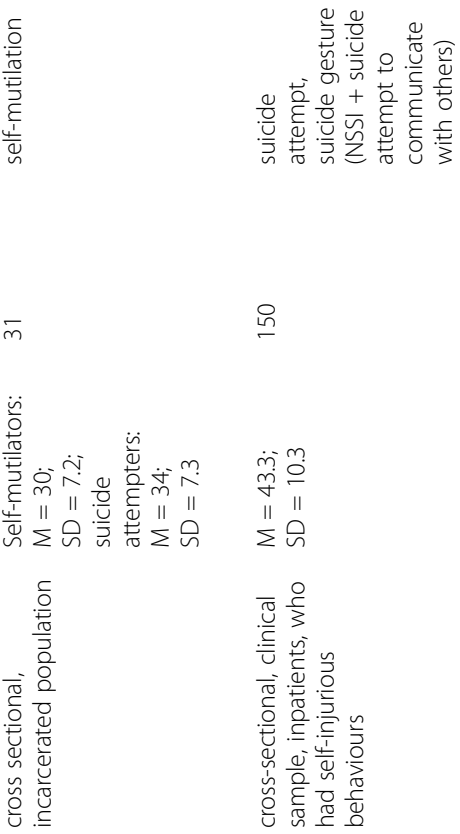

$\overleftrightarrow{s}$

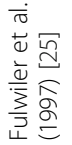

$\stackrel{\Perp}{\longleftarrow}$

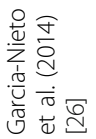

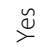

$\overline{\widetilde{\Sigma}}$

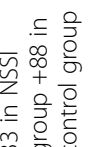

完产毕

ज

$\sum \sum \sum \sum$

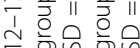

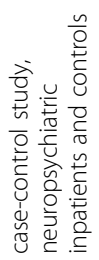

촡

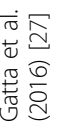




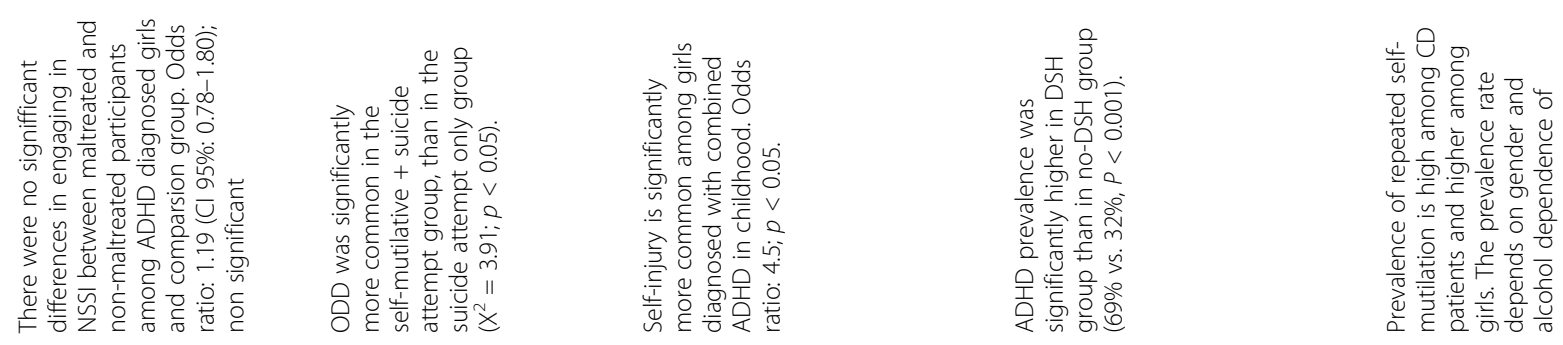

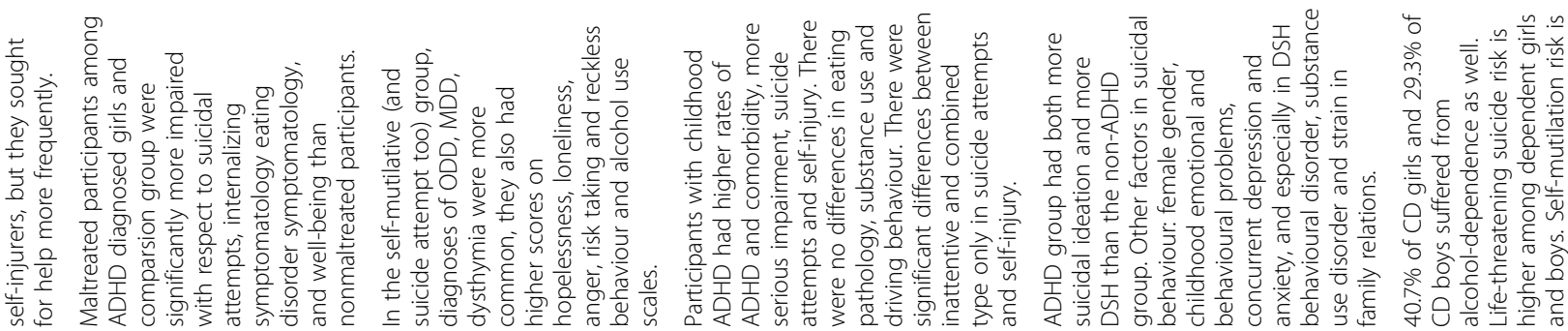
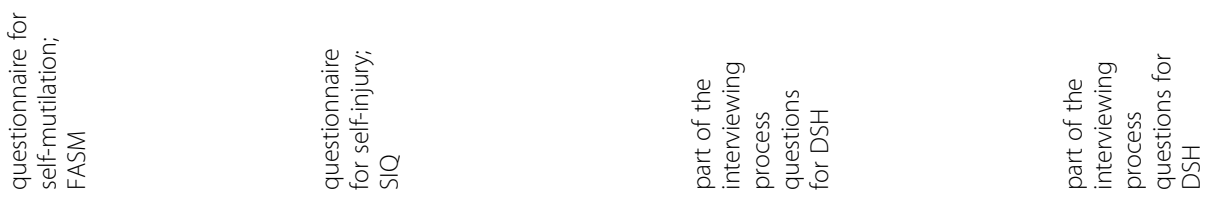

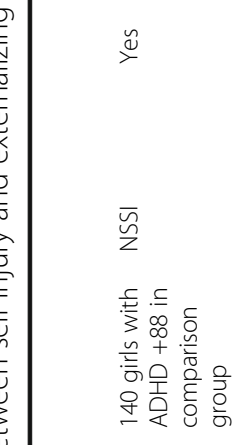

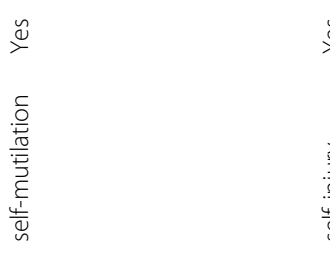

$\stackrel{\varrho}{\longleftarrow}$

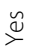

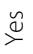

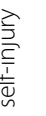

I

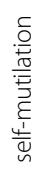

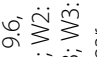

i..

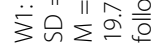

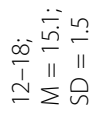

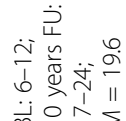

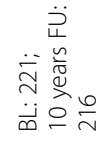

o
+
+
0

$\bar{\Xi}$

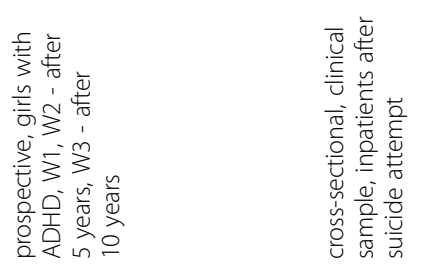

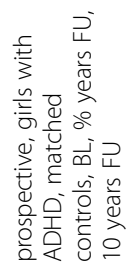

$\frac{\infty}{b}$

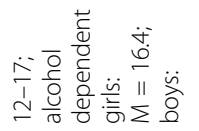

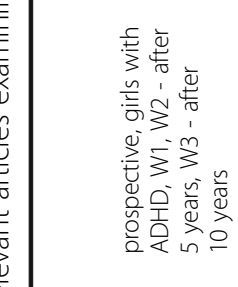

ปั

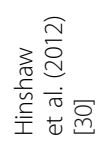

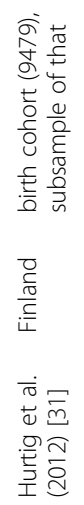

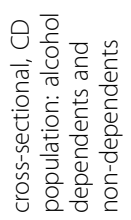

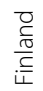

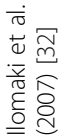




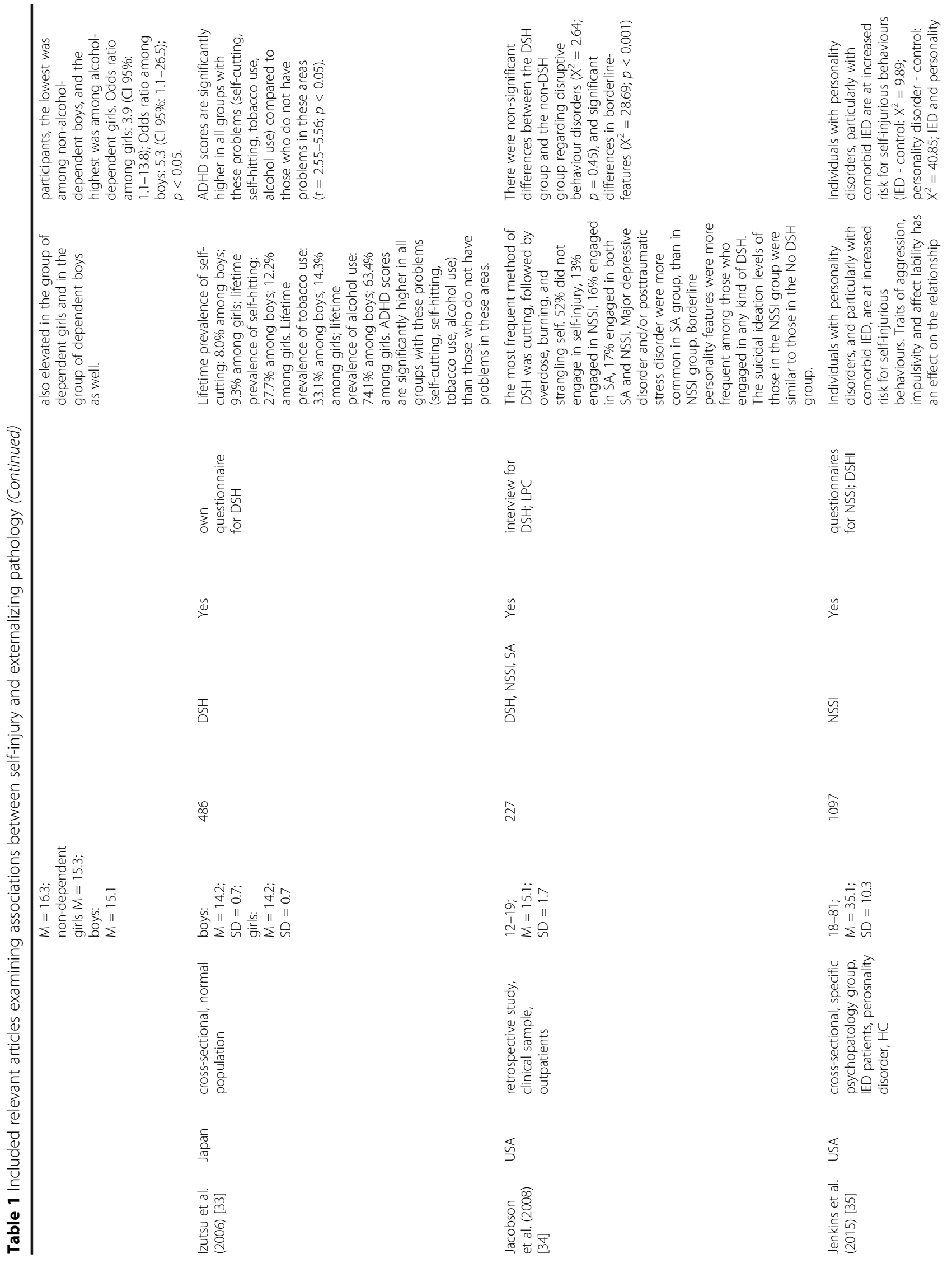




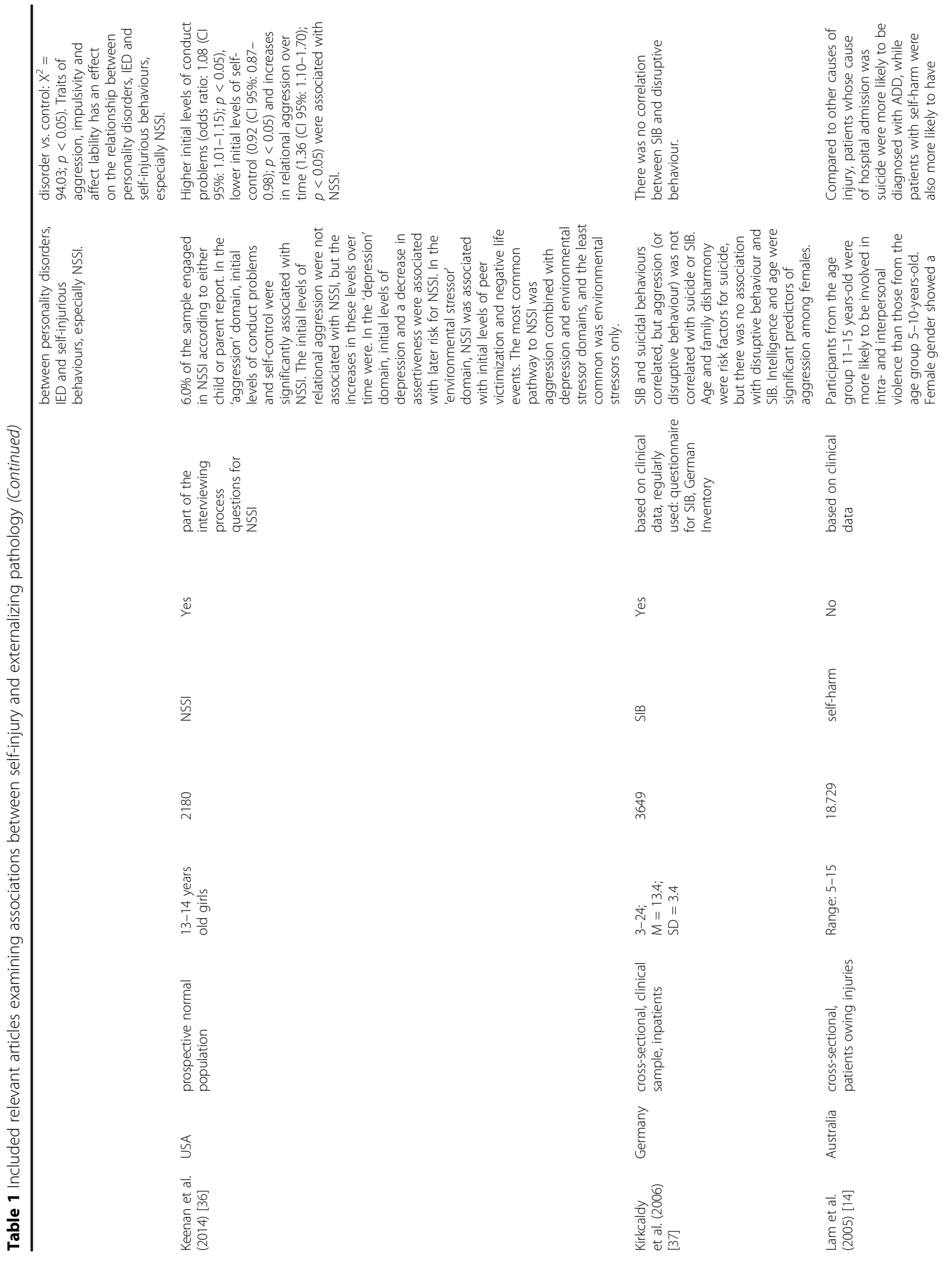




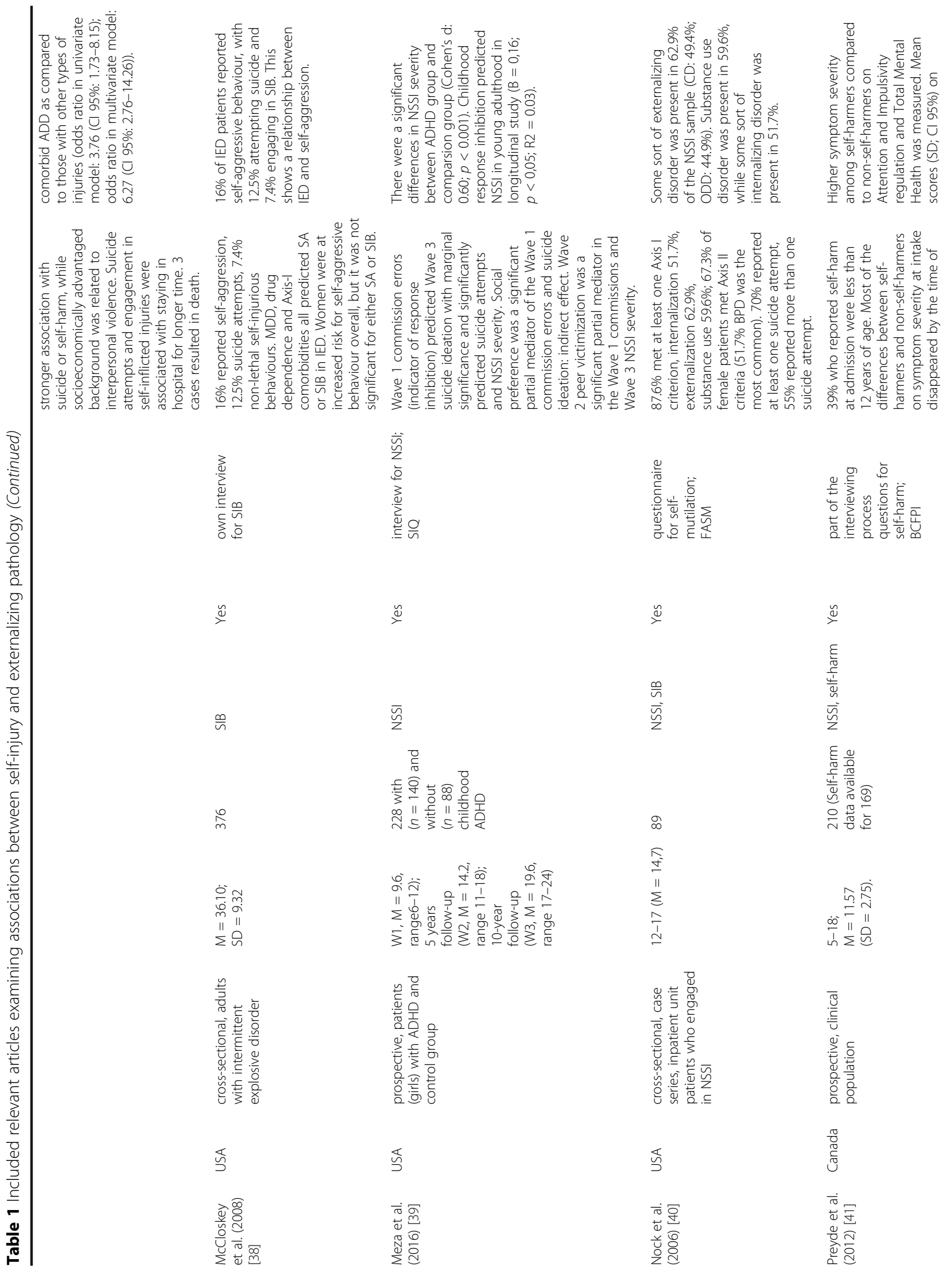




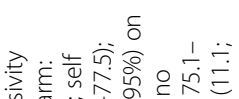

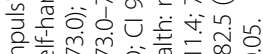

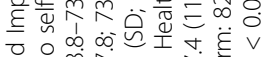

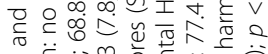

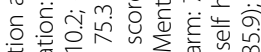

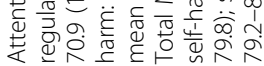

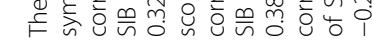

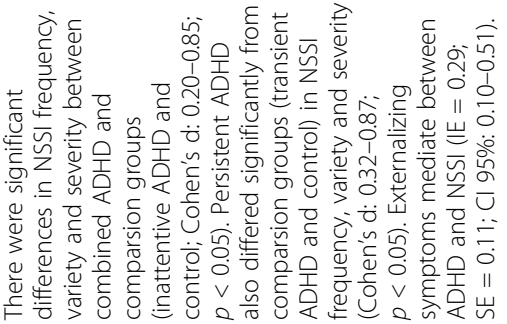

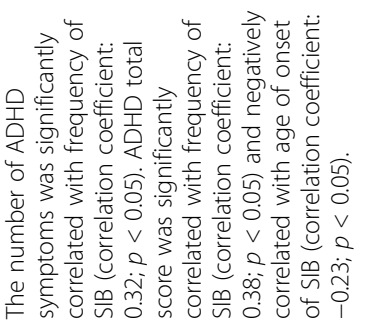

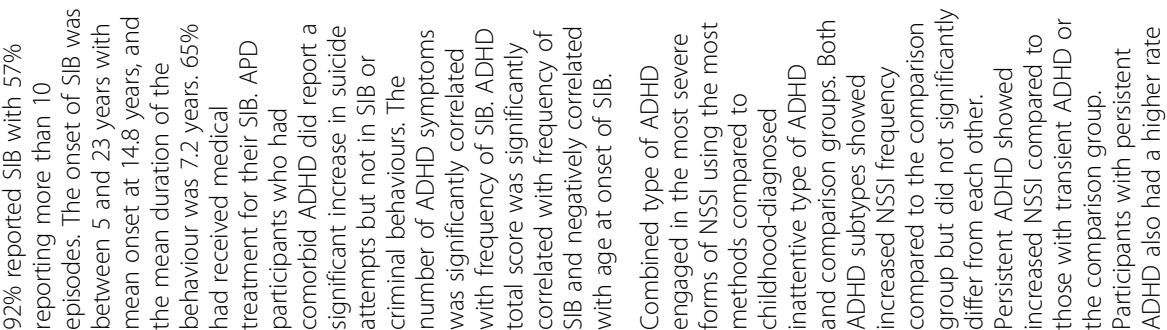

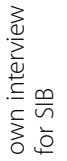

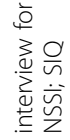

$\stackrel{\Perp}{\check{\nu}}$

$\stackrel{\Perp}{\succ}$

$\stackrel{\varrho}{\sim}$

$\bar{n}$

능

5
$\sum_{i j}^{11}$
$\frac{1}{1}$

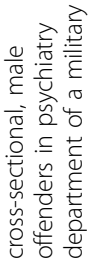

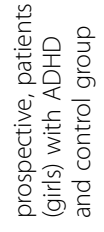

离

ฐ

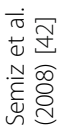

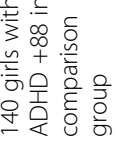

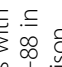

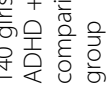

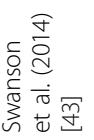



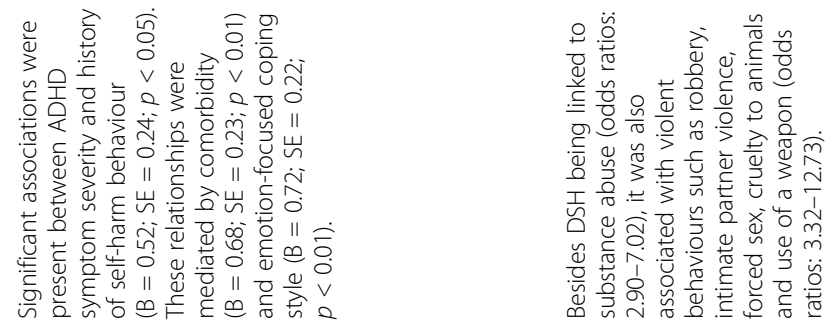

\section{事}

है

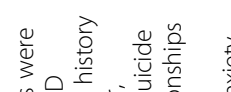

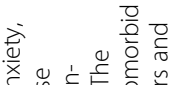

응 -

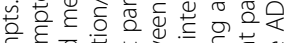

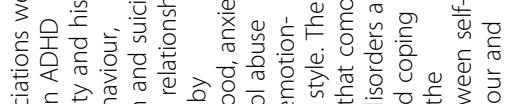

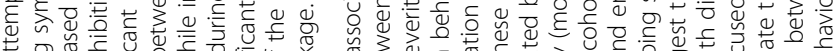

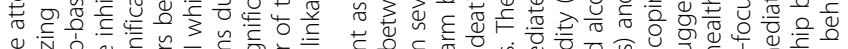

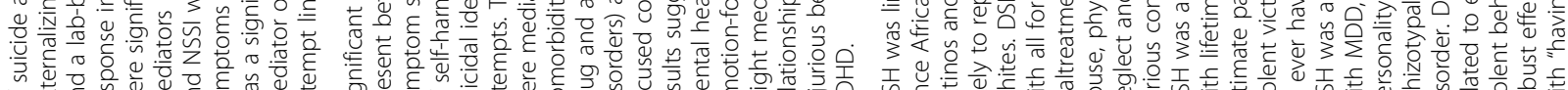

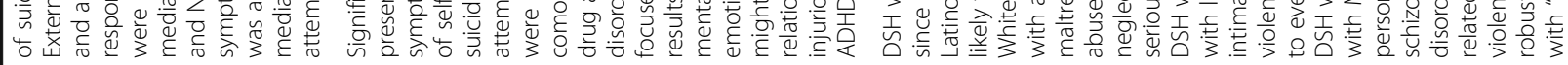

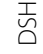

志

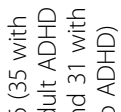

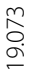

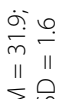

\begin{tabular}{l} 
ò \\
$\infty$ \\
\hdashline
\end{tabular}

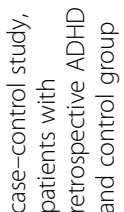

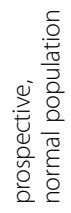

竞亭

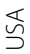

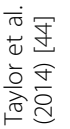



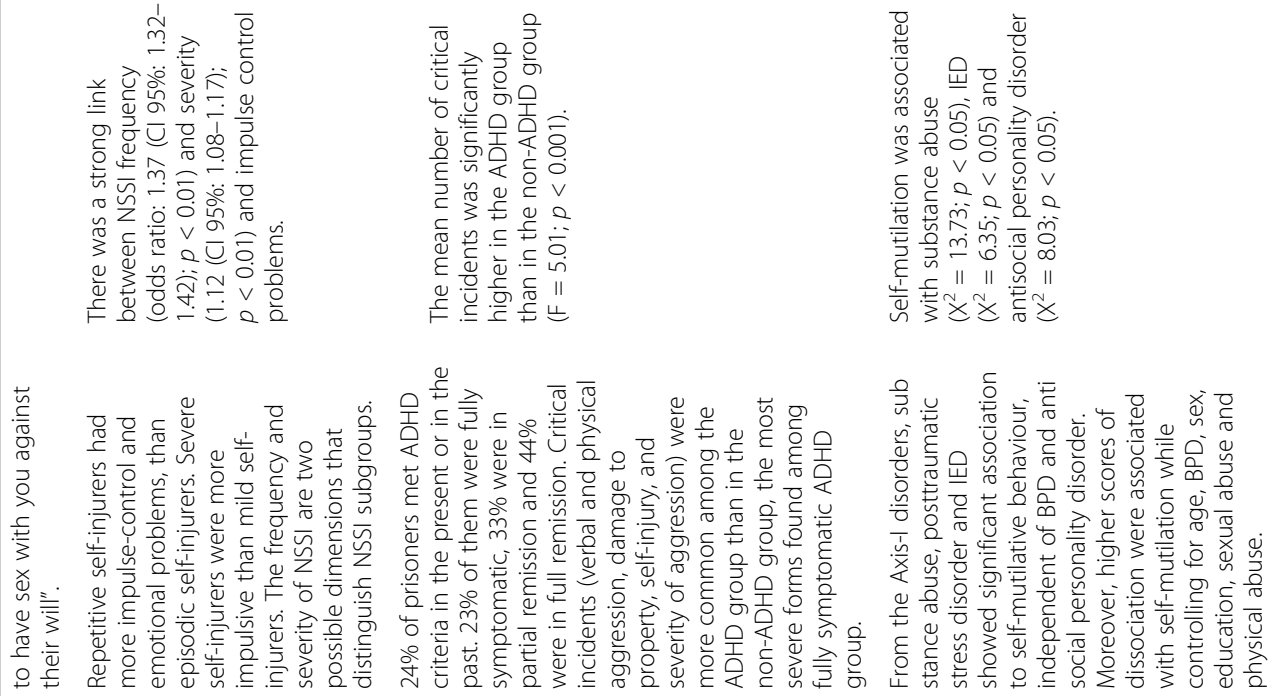

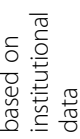

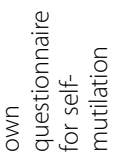

$\stackrel{\check{\varpi}}{\searrow}$

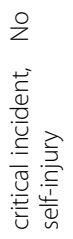

울

$\overline{\bar{n}}$

$\frac{\sqrt{3}}{\frac{5}{4}}$

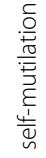

$\underset{\substack{0 \\ 0}}{2}$

$\stackrel{\infty}{\circ}$

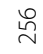

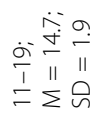

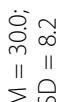

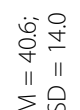

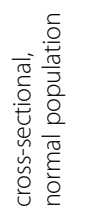

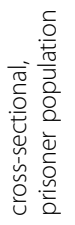

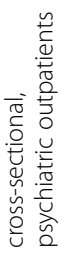

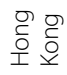

兰

范

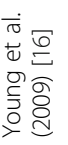


pre-ejection period; RSA: respiratory sinus arrhythmia; SA: suicide attempt; SIB: self injurious behviour; SII: self inflicted injury; SIQ: The suicidal ideation questionnaire; SITBI: Self-Injurious Thoughts and Behaviors Interview.

\section{Terms and definitions for self-injurious behaviours in the included studies}

Below, the different terms and their presence in the reviewed publications are displayed. It is important to clarify that in general the term 'self-injurious behaviours' is used for describing all of these acts, which are not the same as the specific term 'self-injurious behaviour (SIB)'.

In 7 papers there was no clear distinction between the purpose of the investigated self-injurious act (whether it was with suicidal intent or not) [11-17], but in the remaining 28 papers the defined self-injurious behaviour was a nonsuicidal act [18-45].

There were 11 different terms for self-injurious behaviour in the investigated 35 papers.

'NSSI' was the most common term: this expression was presented in 10 studies [27, 28, 34-36, 39-41, 43, 45]. In accordance with the term itself this expression was used only in nonsuicidal meaning. Six studies used only this term for describing the behaviour [27, 35, 36, 39, 43, 45]. In other studies, NSSI could be found as a part of wider self-injurious behaviours: Jacobson et al. [34] use 'deliberate self-harm' (DSH), Nock et al. [40] use 'self-injurious behaviour' (SIB), Preyde et al. [41] and Guendelman et al. [28] use 'self-harm' for describing both suicidal and nonsuicidal self-injurious behaviours. Darke and Torok [22] used 'non-suicidal self-harm' as a term, but their definition was similar to other NSSI definitions.

'DSH' was presented in 6 publications [15, 20, 31, 33, $34,44]$. Four studies used it in a nonsuicidal meaning [20, 31, 33, 44], however, 2 studies [15, 34] did not make this distinction. Five papers $[15,20,31,33,44]$ defined 'DSH' as physical self-injurious behaviour, although Jacobson et al. [34] defined it as a possible overdose act as well. Both Aglan et al. [11] and Chou et al. [12] used the term 'deliberate self-poisoning' (DSP), which they originated from DSH, but only in the meaning of an overdose, they did not make the suicidal-nonsuicidal distinction.

'Self-mutilation' was found in 5 publications [17, 19, $25,29,32]$. The term is used for nonsuicidal physical self-injurious behaviours, except for Zlotnick et al. [17], who did not distinguish the purpose of the act.

'SIB' was a term in 4 papers [37, 38, 40, 42], it is also mainly used in a nonsuicidal meaning, except for Nock et al. [40].

'Self-injury' was presented in 4 papers [18, 24, 30, 45], and 'self-harm' was found in 3 studies [14, 23, 41]. Young et al. [16] used 'self-injury' as a subgroup of 'critical-incidents' that they defined as auto or heteroaggressive acts in an incarcerated population.

There were some other phrases describing self-injurious behaviour: 'parasuicide' [13]: there is no distinction between suicidal-nonsuicidal intent; 'self-inflicted injury' (SII) [21]: this is a nonsuicidal act; 'suicide gesture' [26]: this is a nonsuicidal self-injury or a suicidal attempt to communicate with others.

\section{Measurements of self-injurious behaviours in the included studies}

Among the studies included in our review, diagnostic interviews, self-reported questionnaires and institutional records were used to measure self-injurious behaviours: altogether we found 20 different instruments among the investigated 35 papers.

In 9 cases, the authors designed a longer diagnostic interview, and some questions about self-injurious behaviours were included in it $[11,15,18,19,22,31,32,36,41]$.

An interview specially developed for measuring selfinjurious behaviours was used in 10 studies [13, 21, 26, 28, 30, 34, 38, 39, 42, 43]. The Self-Injurious Thoughts and Behaviors Interview (SITBI) [46] was applied by GarciaNieto et al. [26]. The Lifetime Parasuicide Count (LPC) [47] was used by Jacobson et al. [34], Crowell et al. [13], Crowell et al. [21]. However, in the study of Crowell et al. [21], it was mentioned under a different name: Lifetime-Suicide Attempt Self-Injury (L-SASI). An interviewer-administered modification of the SelfInjurious Questionnaire (SIQ) [48] appeared in the studies of Guendelman et al. [28], Hinshaw et al. [30], Meza et al. [39] and Swanson et al. [43], however these 4 papers are based on the same population. Both McCloskey et al. [38] and Semiz et al. [42] developed their own interview as an instrument for measuring self-injurious behaviours.

Self-report questionnaires were used for measuring self-injurious behaviours in 9 studies $[17,20,23,29,33$, $35,40,44,45]$ in all. Two papers contained question(s) about self-injurious behaviours as a part of a longer questionnaire [23, 45]. Individual questionnaires as an instrument for the measurement of self-injurious behaviours can be found in 7 publications [17, 20, 29, 33, $35,40,44]$. The Deliberate Self-Harm Inventory (DSHI) [49] appears in 3 studies [20, 35, 44]. The Functional Assessment of Self-Mutilation (FASM) [50] was used in 2 studies [29, 40]; the original questionnaire form of SIQ [51] was not applied by any of the investigated papers. Own developed questionnaire was used in 2 papers $[17,33]$.

In the remaining 7 publications, some kind of institutional (health care, prison) records or national databases were the sources of the data on self-injurious behaviours $[12,14,16,24,25,27,37]$. It is important to highlight 
the work of Kirkcaldy et al. [37]: although they based their examinations on the health records of German adolescents and youths, in the region where their study was conducted, the German Inventory Questionnaire which contains questions about SIB - is a regular part of the documentation.

\section{Prevalence of self-injurious behaviour}

Epidemiological data about self-injurious behaviours in different groups can be found in 20 publications (see details below).

Six studies examined the normal population $[15,20$, 23, 33, 36, 45]. Among them 3 papers used the term DSH and found the prevalence rates between 2.9 and $41.9 \%[15,20,33]$. NSSI was a term in 2 publications: with prevalence rates of 6\% [36] and 15\% [45]. Evren et al. [23] used the term 'self-harm', and found its prevalence to be $14.3 \%$.

Five studies investigated general psychiatric populations (inpatients, outpatients or intensive home-based treatment population) $[17,24,34,37,41]$. Among them only one paper used NSSI as a term: Jacobson et al. [34], however they also used DSH to include suicidal behaviour, and they found 13\% prevalence of NSSI and 17\% of DSH. Feingold et al. [24] investigated 'self-injury', and found its prevalence to be $32.4 \%$. Kirkcaldy et al. [37] examined SIB with a prevalence rate of $59 \%$. Preyde et al. [41] studied 'self-harm' and found $34 \%$ as its prevalence rate. 'Self-mutilation' was the term in the study of Zlotnick et al. [17], and the prevalence rate was $33.2 \%$.

In the study of Carli et al. [19] there was an incarcerated population. They found the prevalence of 'self-mutilation' to be $17.0 \%$.

In the remaining 8 studies, the aim of the investigation was to compare a group having a specific psychopathology with a healthy control group or with a group having another psychopathology.

Four publications examined attention deficit hyperactivity disorder (ADHD) as a group with specific psychopathology [12, 18, 30, 31]. Among ADHD patients versus non-ADHD patients, there was a robust difference in the prevalence rates of self-injurious behaviours. Prevalence of self-injury was $50.6 \%$ in the combined type of ADHD, versus $28.9 \%$ in the inattentive type of ADHD, versus $19 \%$ in the non-ADHD control group [30]. Prevalence of self-injury among drug dependent patients with ADHD was $47.7 \%$, versus $25.2 \%$ without ADHD [18]. Prevalence of DSH was 69\% in an ADHD group and $32 \%$ in a control group [31]. In one study there was a significant difference in the incidence of DSP: it was 6.13/10,000 persons/years in the ADHD group and 1.36/ 10,000 persons/years in the control group [12].

Two studies examined intermittent explosive disorder (IED) as a specific psychopathology. McCloskey et al.
[38] found the prevalence of SIB to be 16\% in this group. Jenkins et al. [35] investigated participants with personality disorder with or without IED: they found the prevalence of NSSI to be $18 \%$.

Only in one publication could data be found on the prevalence of self-mutilation among participants with conduct disorder (CD) [32]: they found its prevalence between 15.5 and $62.5 \%$. It depends on the gender and alcohol dependence of participants, with the lowest prevalence being among non-alcohol-dependent boys, and the highest being among alcohol-dependent girls. However there was another study, which examined the prevalence of SIB among psychiatric offenders in a military institution with antisocial personality disorder [42]: the prevalence rate of SIB was $92.0 \%$.

\section{Correlations of self-injurious behaviours and externalizing psychopathology}

Fifteen publications investigated the associations between self-injurious behaviours and ADHD [12, 14, 16, $18,21,23,25,28,30,31,33,41-44]$. Four of them studied ADHD versus non-ADHD groups, and found robust differences in the prevalence or incidence rates of self-injurious behaviours (self-injury $[18,30]$; DSH [31]; DSP [12]). Higher symptom severity or higher scores on ADHD symptom scales or higher numbers of ADHD symptoms are associated with self-injurious behaviour in 6 papers: ADHD scores were higher in the SII group than in the control group or depressed group [21]; ADHD scores were higher in the self-harm group versus non-self-harm group [23]; and in the DSH group versus non-DSH group [33]; frequency of SIB was correlated with the number of ADHD symptoms [42]; those who engaged in self-harm in a residential treatment or intensive home-based treatment programme had higher ADHD symptom severity than those who did not engage in this behaviour [41]; and there was a significant association between symptom severity of ADHD and history of DSH behaviours [44]. Moreover, Fulwiler et al. [25] found the importance of childhood ADHD in adulthood self-mutilation among prisoners. Lam et al. [14] underline that the odds ratio of having comorbid attention deficit disorder (ADD) is 3 times higher in the self-harm group than in the non-selfharm group. Swanson et al. [43] found that both the inattentive and combined type of ADHD were associated with NSSI, however more severe forms and higher frequency of NSSI are more likely to be associated with the combined type. Young et al. [16] emphasize that the number of critical incidents (including self-injury) were higher among people with ADHD in an incarcerated population. According to the work of Guendelman et al. [28], maltreatment is a strong risk factor of both NSSI and any other self-harm acts (suicide attempts), 
and there is no significant difference in this risk effect between girls diagnosed with ADHD and comparison group.

Twelve publications examined the possible connection between conduct disorder (CD) or CD symptoms or antisocial personality disorder in adulthood and selfinjurious behaviours $[11,15,20-22,26,32,34,36,37$, $40,42]$. Seven of them found significant positive associations: CD is a risk factor of adulthood DSP repetition [11]; both $\mathrm{CD}$ and oppositional defiant disorder (ODD) correlated with DSH, however there is no significant difference in the level of correlation between them [20]; there were higher CD scores in the SII group than in the control group or depressed group [21]; antisocial personality disorder is a risk factor of suicidal gestures (included self-injurious behaviour) [26]; prevalence of self-mutilation is high among CD patients, especially when they are girls and they are also alcohol-dependent [32]; higher initial levels of conduct problems are associated with NSSI [36]; and DSH is linked to violent behaviours (robbery, intimate partner violence, forced sex, cruelty to animals, use of a weapon) [15]. Two publications described a non-significant positive connection: $C D$ symptoms are more frequent in a non-suicidal self-harm group than in the control group [22]; frequency of any disruptive behaviours was higher both in DSH and in NSSI groups than in the control group [34]. Nock et al. [40] found the presence of CD to be $49.4 \%$ in their $100 \%$ NSSI sample. Semiz et al. [42] found the prevalence of SIB to be $92 \%$ in a $100 \%$ antisocial personality disorder sample. However Kirkcaldy et al. [37] could not find any association between SIB and disruptive behaviour.

Four papers studied the link between oppositional defiant disorder (ODD) and self-injurious behaviours or SIB. Cerutti et al. [20] found, that ODD correlated with DSH but they did not find a significant difference with the correlation of $\mathrm{CD}$ and DSH. In the study of Crowell et al. [21], there are higher ODD scores in the SII group than in the depressed group or control group. Guertin et al. [29] found that ODD was more common in both the selfmutilator and suicide attempter group than in the suicide attempter only group. In Nock et al. [40], in the 100\% NSSI sample the presence of ODD was $44.9 \%$.

There are 3 publications that strengthen the relationship between intermittent explosive disorder and self-injurious behaviours (NSSI [35]; SIB [38]; self-mutilation [17]).

There was information about general externalizing symptoms in 5 publications. Crowell et al. [13] examined parasuicidal versus non-parasuicidal groups; in the parasuicidal group the $\mathrm{T}$-scores of externalizing symptoms were significantly higher. Crowell et al. [21] investigated the SII group, control group and depressed group: Tscores of externalizing psychopathology were also significantly higher in the SII group than in the control or depressed groups. In the 100\% NSSI sample of Nock et al. [40] the presence of any externalizing disorder was $62.9 \%$ while the presence of any internalizing disorder was $51.7 \%$. Feingold et al. [24] did not study the direct link between externalizing pathology and self-injury, but they found a strong link between alcohol abuse and selfinjury, and also described the association between externalizing pathology and alcohol abuse. Gatta et al. [27] examined neuropsychiatric inpatients who engaged in NSSI and controls from high schools. They found significantly higher externalizing scores in the NSSI group than in the control group according to both self-report and parent-report.

In the remaining 3 studies, the authors examined traits of externalizing psychopathology: Carli et al. [19] found a significant difference in the prevalence of selfmutilation between high-impulsive and low-impulsive groups. You et al. [45] investigated the role of impulsecontrol problems in the frequency and severity of NSSI and found individuals with more impulse-control problems had more severe and frequent NSSI behaviour. Meza et al. [39] found the importance of response inhibition in the prediction of NSSI among individuals with or without ADHD.

\section{Self-injury and suicide}

In total 8 of the 35 articles assessed the relationship between self-injury and suicide [22, 25, 26, 29, 31, 32, 34, 43]. To compare results by age groups, we will first overview 3 papers that studied adult samples [22, 25, 26] and then turn to the other 4 studies that assessed adolescence populations $[29,31,32,34]$ and one longitudinal study that assessed young girls $(\mathrm{M}=9.1$ years $)$ with 5 and 10 years follow-ups [43].

In their study on adult injecting drug users, Darke and Torok [22] assessed if the two phenomena (NSSI and suicidality) overlap. They found that $42.3 \%$ of those who reported NSSI also reported suicide attempt, and 39\% of those who reported suicide attempt had also engaged in NSSI. In $83.3 \%$ of the cases with both suicidal and NSSI, the NSSI was present prior to suicide attempts.

The other two studies on adult samples focused on the differences between suicidal and NSSI behaviours $[25,26]$.

In an adult prisoner sample, Fulwiler et al. [25] found differences between those committing suicide attempts and self-mutilation regarding their methods (more lethal methods in suicide attempt) and frequency (higher frequency in case of self-mutilation). The two groups also differed in psychiatric comorbidities: diagnosis of an affective disorder was present in $87 \%$ of the suicide attempt group compared to $19 \%$ in self-mutilators, while a syndrome of mixed anxiety/dysthymia patterns present from childhood or adolescence $(56 \%$ in self- 
mutilation group) and history of childhood hyperactivity ( $75 \%$ vs $7 \%$ ) characterized the self-mutilation group.

Garcia-Nieto et al. [26] also focused on the differences between self-injurers with and without intent to die. Their results pointed out the differences in the prevalence of certain personality disorders: histrionic personality disorder (HPD) ( $0 \%$ in neither gestures nor attempts; $46.7 \%$ in gestures; $1.6 \%$ in attempt, $12.5 \%$ in attempts + gestures group) and antisocial personality disorder (APD) (5.3\% in neither gestures nor attempts; $6.7 \%$ in gestures; $4.8 \%$ in attempt, $1.2 \%$ in attempts + gestures group) as risk factors were associated with suicide gestures. Narcissistic personality disorder (NPD) (27\% in suicide attempt group, $0 \%$ in all other groups) showed association with suicide attempts, and BPD (7\% in neither gestures nor attempts; $33.3 \%$ in gestures, $9.7 \%$ in attempts, $43.8 \%$ in gesture + attempt group) seemed to be a risk factor for both suicide gestures and attempts.

In an adolescent community sample [31], those with ADHD reported more suicidal ideation $(57 \%$ vs. $28 \%$, $P<0.001)$ and DSH $(69 \%$ vs. $32 \%, P<0.001)$ than those who did not have the disorder. Female gender and depression/anxiety were also associated with both suicidal ideation and DSH, while behavioural disorder, substance use and certain family factors (e.g. living in nonintact family, living in family with financial problems) were associated with DSH but not with suicidal ideation and acts.

In an adolescent inpatient sample, those who not only had a history of suicide attempt but also a history of selfmutilative behaviour were significantly more likely to have a diagnosis of ODD $\left(\chi_{2}{ }_{1}(N=75)=3.91, p<.05\right)$; major depressive disorder (MDD; $\mathrm{X} 2_{1}(N=76)=13.74, p<.01$; $)$ and dysthymia $\left(\mathrm{X}_{1}(N=76)=4.82, p<0.05\right)$, and had higher scores of loneliness $(\mathrm{F}=8.24, p<0.05)$, anger $(\mathrm{F}=11.88, p<0.05)$, risk taking $(\mathrm{F}=16.31, p<0.05)$ and reckless behaviour $(\mathrm{F}=7.21, p \leq 0.005)$ [29].

Jacobson et al. [34] studied an adolescent outpatients sample with no DSH (52\%), NSSI only (13\%), suicide attempt only (16\%) and with both NSSI and suicide attempt (17\%). They found that the only psychiatric diagnosis in which those engaging in NSSI differed from those who had not engaged in any type of DSH was BPD. When distinguishing between DSH groups, differences were found in the likeliness of comorbid depression, posttraumatic stress disorder (PTSD) and in the levels of suicidal ideation. Regarding MDD, with the NSSI only group as the comparison group and controlling for gender, the suicide attempt only group (odds ratio $-\mathrm{OR}=3.43 ; 95 \% \mathrm{CI}=1.17-10.00 ; p=0.03$ ) and the suicide attempt and NSSI group (OR $=3.55 ; 95 \%$ confidence interval $-\mathrm{CI}=1.24-10.16 ; p=0.02$ ) were more likely to have depression. Regarding PTSD, when controlling for gender, participants in the suicide attempt only group $(\mathrm{OR}=8.93 ; 95 \% \mathrm{CI}=1.04-76.92$; $p=0.046)$ and the suicide attempt and NSSI group $(\mathrm{OR}=10.09 ; 95 \% \mathrm{CI}=1.18-85.97 ; p=0.035)$ were more likely to have PTSD diagnosis than those in the NSSI-only group. The NSSI-only group also reported significantly lower levels of suicidal ideation scores than the other DSH groups: Suicide attempt only (adjusted mean difference $=-20.24, p<0.001$ ) and suicide attempt and NSSI group (adjusted mean difference $=-25.92 ; p<0.001)$. Meanwhile the two other DSH groups (suicide attempt only and suicide attempt and NSSI groups) did not significantly differ from each other regarding the rates of MDD, PTSD and the levels of suicidal ideation.

Swanson et al. [43] studied girls recruited from both a clinical and non-clinical background in their followup study (age at baseline: $M=9.1$ years; age at Wave 2: $M=14.2$ years; age at Wave $3: M=19.6$ years). According to their findings, externalizing symptoms and inhibition/impulsivity might be significant partial mediators between Wave1 ADHD and W3 NSSI scores (indirect effect $-\mathrm{IE}=0.29$; standard error $-\mathrm{SE}=0.11$; CI95 = 0.10-0.51); while Wave 2 internalizing symptoms might be a significant partial mediator of the Wave 1 ADHD Wave 2 suicide attempt linkage $(\mathrm{IE}=0.11 ; \mathrm{SE}=0.05 ; \mathrm{CI} 95=0.03-0.25)$.

Ilomaki et al. [32] did not investigate the association between the two phenomena but they found that alcohol dependence was a common potential risk factor for both phenomena since it increased the risk for both suicide attempts 3.8 -fold [CI95 $=1.06-13.44$; $p=0.041]$ and self-mutilation 3.9-fold (CI95 $=1.09-$ $13.76 ; p=0.037)$ among adolescent girls with DSMIV-diagnosed CD.

\section{Discussion}

In the current systematic review, 35 papers examining the correlation between externalizing psychopathology and self-injurious behaviours are summarized.

Consistent with the review on internalizing pathology and NSSI [7], we found wide-ranging terminology for self-injury: 11 different terms were used in 35 papers. Among these terms NSSI has the clearest definition, suggested by the 'International Society for the Study of Self-injury' (ISSS) in 2007 [2] and by DSM-5 [1]. DSH is the most unstable term, because it has many definitions, some authors use it only in a nonsuicidal meaning [20,31,33,44], while others use it as non-fatal but with both suicidal and nonsuicidal meanings [15, 34]. The other issue is that self-poisoning was not included in the definition by most of the authors $[15,20,31,33$, 44], but Jacobson et al. [34] use the term DSH both for physical self-damage and overdose cases as well. 
Moreover, DSP appeared as an individual term for selfpoisoners $[11,12]$. SIB is mostly defined as both suicidal and non-suicidal self-injurious behaviour, but selfpoisoning is not included in the definition [37, 38, 40, 42]. Summarizing the main issues of defining self-injurious behaviour are the following: whether the definition used should include self-poisoning or not, and whether it should be clarified as a suicidal or a nonsuicidal act. For example, Kapur et al. [52] questioned the concept of NSSI, because in some cases it is impossible to decide if the act was with suicidal intent or not, especially in an adolescent population. Nock [53] drew attention to this definition problem in his earlier review; while sometimes those who have engaged in self-injury cannot themselves clarify their intent, conceptually it is important to make this distinction. Brunner, Kaess et al. [10] made the distinction between self-poisoning and self-harming by focusing on the surface of the body.

The heterogeneity that is present in the terminology and definitions of self-injurious behaviours is also reflected in the diversity of instruments used to assess the phenomenon. The most frequently used instruments (LPC [13, 21, 34]; DSHI [20, 35, 44]) were present in no more than three plus three out of the 35 studies. Among the studies included in our review, diagnostic interviews, self-reported questionnaires, institutional (health care, prison) records and national databases were used to measure self-injury. In more than half of the papers $(18 / 35)$ the method was an interview, or special questions as part of a longer interview [11, 13, $15,18,19,21,22,26,28,31,32,34,36,38,39,41-43]$. The instruments were based on the previously described different definitions of self-injury and therefore they may measure somewhat different phenomena. This may be one of the factors that make it difficult to compare the results of different studies, as we have already highlighted above.

The prevalence rates of different self-injurious behaviours vary greatly both in clinical samples (13.0$59.0 \%)$ and in normal population based samples (2.9$41.9 \%$ ). This variance can be explained partially by the definition and measurement heterogeneity, described above. However, using one term (e.g. NSSI) does not lead to more homogenous prevalence rates. In the specific psychopathology groups investigated, the diversity of prevalence rates could also be observed. Due to this heterogeneity, and with the aim of avoiding confusion, the original terms used by the authors of the papers are used in the 'Results' section, and the prevalence rates are mentioned in parallel. These various results underline the importance of standardized terminology and measurement for self-injurious behaviours, which would make the results of future studies comparable.
There were significantly higher prevalence rates in ADHD groups than in control groups [12, 18, 30, 31]. Moreover, the papers found higher ADHD symptom severity in self-injurer groups [21, 23, 33, 41, 42, 44]. The most severe and frequent forms of NSSI can be found in the combined types of ADHD versus the inattentive type and the control group [43], that strengthen the role of impulsivity in self-injurious behaviours, which is an important risk factor of selfinjurious behaviours. However, according to Hamza et al. [54], itis very complicated to measure, especially with self-reported questionnaires. Moreover, it seems that different aspects of impulsivity have different roles on self-injury. Mood-based impulsivity influences the initiation of self-injury, cognitive facets of impulsivity are related to the maintenance of self-injury and behavioural impulsivity is associated with self-injury under conditions of negative affect [55].

In addition to the finding that ADHD and selfinjurious behaviours are strongly associated, which is in agreement with a previous review on this topic [8], we found evidences for the association between selfinjurious behaviours and other externalizing psychopathology. There are high prevalence rates of self-injurious behaviours among patients with CD (15.5-62.5\%, it depends on the gender and alcohol dependence of participants [32]. Semiz et al. [42] found the prevalence rate of SIB to be $92.0 \%$ among male offenders with antisocial personality disorder. Moreover, there were higher $C D$ scores in the self-injurer group, than in the control group [21]; and in 6 further studies there are strong links between $\mathrm{CD}$ or disruptive symptoms and selfinjurious behaviours $[11,15,20,26,32,36]$. Only one paper from the 12 investigated could not find a link between $\mathrm{CD}$ and self-injury [37]. The relationship between self-injurious behaviours and ODD is underlined by 3 papers $[20,21,29]$, and there is a connection with intermittent explosive disorder as well according to 3 studies $[17,35,38]$. General externalizing symptoms are also more frequent in self-injurer groups [13, 21]. Nock et al. [40] found higher externalizing comorbidity than internalizing in self-injurer groups.

Although the aim of this review was not specifically to explore the relationship between NSSI and suicidality, 8 out of the 35 articles contained results regarding this topic. Although the two phenomena might overlap [22, 34] and might have shared clinical characteristics such as BPD [26], depression and anxiety [31] or alcohol dependence [32], most of these articles focused on factors distinguishing between suicide and NSSI. Those with and without suicidal intent might show differences in the frequency and methods of their self-injuring, comorbid symptoms and personality disorders [25, 26]. Some results show that while 
externalizing symptoms are associated with NSSI [25, 43], internalizing symptoms might play a bigger role in suicidality $[25,34,43]$; while others found higher numbers of both internalizing and externalizing symptoms among those who reported both suicidal behaviour and NSSI $[29,31]$.

\section{Limitations}

The main limitation of our review is the heterogeneity of both the terminology and instruments, as we mentioned above, which makes it hard to compare the results of the included papers. In most of the cases, the distinction that the act was with or without suicidal intent was clear, however, among these 35 papers there were 7 papers, where this distinction was not clarified [11-17]. The fact that similar terms for self-injurious behaviour were also measured with multiple instruments in different studies also complicates the understanding of the topic.

A further limitation is that we may be missing some relevant papers on this topic. Firstly, because we included only articles that are written in English. Secondly, we have chosen the standard method and searched for publications in large indexed literature databases. This led to 14 papers on the topic of ADHD and self-injury, however, Allely [8] used a less conservative search method and checked 'Google Scholar' as well and found 15 articles on the topic of ADHD and NSSI, which is a sub-topic of our review topic. There were small differences in our keywords as well, that could also be an explanation for the differences in our findings. They used 'self-poisoning' as a search word as well. Finally there were 5 overlapping publications $[25,30,31,33,42]$, but they found 9 publications that we did not (5 of them fit our inclusion criteria as well, but they had not appeared in our search) and we found 3 articles in their time window, that they had not $[18,21,41]$. The remaining 5 publications we found miss their time window [12, 14, 23, 43, 44]. In spite of all these differences in the papers, Allely [8] also concluded that ADHD and self-injury have a strong association, as we did, so these results support each other. Finally, it is important to underline that our aim was not to focus only on ADHD but on the whole spectrum of externalizing disorders.

Another methodological limitation could be that our work is a narrative review. A meta-analytic review, or a full meta-analysis would be more useful to compare the results of these very heterogenous papers. To handle this limitation and make the comparisons easier, sample sizes, design of the original studies and statistical results are presented in Table 1.

Another limitation could be that since our focus in this review was to investigate the association between
NSSI and externalizing pathology, the role of externalizing problems in the relationship between NSSI and suicidality might be overrepresented, while other important factors might remain hidden. A review focusing directly on the NSSI-suicidality relationship, including two of the articles discussed in this paper [29,34] was just recently published [56]. According to their conclusion, the two phenomena are correlated and share similar vulnerabilities and risk factors, moreover, NSSI itself is found to be a risk factor for suicidal behaviour.

\section{Conclusions}

In conclusion, reviewing these 35 papers on self-injury and externalizing psychopathology underlines the confusion in terminology on self-injurious behaviours, which could lead to difficulty in comparing studies on the topic. Based on our findings, we suggest the use of the term NSSI in future studies, as NSSI has the most precise definition. Furthermore, it became an individual diagnostic category in DSM-5 [1].

Summarizing the results of these papers - although the connection between internalizing pathology and selfinjurious behaviours are well-studied [7] - there is a strong association between self-injurious behaviours and externalizing pathology and individual externalizing disorders as well. Based on this knowledge, it seems to be important to investigate the presence of parallel internalizing and externalizing pathology and its connection to NSSI, because it may help to identify the most endangered populations.

\section{Abbreviations}

ADHD: Attention deficit hyperactivity disorder; APD: Antisocial personality disorder; BPD: Borderline personality disorder; CD: Conduct disorder;

Cl: Confidential interval; DSH: Deliberate self-harm; DSHI: Deliberate Self-Harm Inventory; DSM: Diagnostic and Statistical Manual of Mental Disorders; DSP: Deliberate self-poisoning; FASM: Functional Assessment of SelfMutilation; HPD: Histrionic personality disorder; IE: Indirect effect; IED: Intermittent explosive disorder; ISSS: International Society for the Study of Self-injury; LPC: Lifetime Parasuicide Count; L-SASI: Lifetime-Suicide Attempt Self-Injury; MDD: Major depressive disorder; NPD: Narcissistic personality disorder; NSSI: Nonsuicidal self-injury; ODD: Oppositional defiant disorder; OR: Odds ratio; PTSD: Posttraumatic stress disorder; SE: Standard error; SIB: Self injurious behviour; SII: Self inflicted injury; SIQ: Self-Injurious Questionnaire; SITBI: Self-Injurious Thoughts and Behaviors Interview

\section{Acknowledgement}

Judit Balazs was supported by the János Bolyai Research Scholarship of the Hungarian Academy of Sciences.

This work was supported by OTKA K108336 grant.

\section{Funding}

There were no direct funding for any part of this study. General funding supports of our research group can be found in the 'Acknowledgement' section. The open access publication fee is warranted by the first author's university according to an agreement between BMC and Semmelweis University

Availability of data and materials Not applicable. 


\section{Authors' contributions}

GM participated in the design of the study, performed the literature search, participated in the data analysing and drafted the manuscript. $\mathrm{LOH}$ participated in the design of the study and in the data analysing and drafted the manuscript. JB participated in the design of the study, coordinated the steps of the data analysing and drafted the manuscript. All authors read and approved the final manuscript.

\section{Competing interests}

The authors declare that they have no competing interests.

\section{Consent for publication}

Not applicable.

\section{Ethics approval and consent to participate}

Not applicable.

\section{Publisher's Note}

Springer Nature remains neutral with regard to jurisdictional claims in published maps and institutional affiliations.

\section{Author details}

'Semmelweis University, Mental Health Sciences School Of Ph.D., Üllői út 26, Budapest 1085, Hungary. ${ }^{2}$ Vadaskert Child Psychiatry Hospital and Outpatient Clinic, Lipótmezei út 1-5, Budapest 1021, Hungary. ${ }^{3}$ Doctoral School of Psychology, Eötvös Loránd University, Izabella utca 46, Budapest, Hungary. ${ }^{4}$ Institute of Psychology, Eötvös Loránd University, Izabella utca 46, Budapest, Hungary.

\section{Received: 25 October 2016 Accepted: 24 April 2017} Published online: 03 May 2017

\section{References}

1. American Psychiatry Association. Diagnostic And Statistical Manual Of Mental Disorders 5th edn. (DSM-5). Washington DC: American Psychiatry Association; 2013.

2. Ross S, Heath NL, Toste JR. Non-suicidal self-injury and eating pathology in high school students. Am J Orthop. 2009;79:83-92.

3. American Psychiatry Association. Diagnostic And Statistical Manual Of Mental Disorders 4th edn. (DSM-IV). Washington DC: American Psychiatry Association; 1994.

4. Glenn CR, Klonsky ED. Nonsuicidal self-injury disorder: an empirical investigation in adolescent psychiatric patients. J Clin Child Adolesc Psychol. 2013;42:496-507.

5. Zetterqvist M. The DSM-5 diagnosis of nonsuicidal self-injury disorder: a review of the empirical literature. Child Adolesc Psychiatry Ment Health. 2015:9:31.

6. Fox KR, Franklin JC, Ribeiro JD, Kleiman EM, Bentley KH, Nock MK. Metaanalysis of risk factors for nonsuicidal self-injury. Clin Psychol Rev. 2015;42: 156-67.

7. Bentley KH, Cassiello-Robbins CF, Vittorio L, Sauer-Zavala S, Barlow DH. The association between nonsuicidal self-injury and the emotional disorders: A meta-analytic review. Clin Psychol Rev. 2015;37:72-88.

8. Allely CS. The association of ADHD symptoms to self-harm behaviours: a systematic PRISMA review. BMC Psychiatry. 2014;14:133.

9. Csorba J, Dinya E, Plener P, Nagy E, Pali E. Clinical diagnoses, characteristics of risk behaviour, differences between suicidal and non-suicidal subgroups of Hungarian adolescent outpatients practising self-injury. Eur Child Adolesc Psychiatry. 2009;18:309-20.

10. Brunner R, Kaess M, Parzer P, Fischer G, Carli V, Hoven CW, Wasserman C, Sarchiapone M, Resch F, Apter A, Balazs J, Barzilay S, Bobes J, Corcoran P, Cosmanm D, Haring C, losuec M, Kahn JP, Keeley $H_{\text {, }}$ Meszaros G, Nemes B, Podlogar T, Postuvan V, Saiz PA, Sisask M, Tubiana A, Varnik A, Wasserman D. Life-time prevalence and psychosocial correlates of adolescent direct self-injurious behavior: a comparative study of findings in 11 European countries. J Child Psychol Psychiatry Allied Discip. 2014;55:337-48.

11. Aglan A, Kerfoot M, Pickles A. Pathways from adolescent deliberate selfpoisoning to early adult outcomes: a six-year follow-up. J Child Psychol Psychiatry Allied Discip. 2008;49:508-15.
12. Chou IC, Lin CC, Sung FC, Kao CH. Attention-deficit hyperactivity disorder increases the risk of deliberate self-poisoning: A population-based cohort. Eur Psychiatry. 2014;29:523-7.

13. Crowell SE, Beauchaine TP, McCauley E, Smith CJ, Stevens AL, Sylvers P. Psychological, autonomic, and serotonergic correlates of parasuicide among adolescent girls. Dev Psychopathol. 2005;17:1105-27.

14. Lam LT. Attention deficit disorder and hospitalization owing to intra- and interpersonal violence among children and young adolescents. J Adolesc Health. 2005:36:19-24.

15. Vaughn MG, Salas-Wright CP, DeLisi M, Larson M. Deliberate self-harm and the nexus of violence, victimization, and mental health problems in the United States. Psychiatry Res. 2015;225:588-95.

16. Young S, Gudjonsson GH, Wells J, Asherson P, Theobald D, Oliver B, Scott C, Mooney A. Attention deficit hyperactivity disorder and critical incidents in a Scottish prison population. Personal Individ Differ. 2009;46:265-9.

17. Zlotnick C, Mattia Jl, Zimmerman M. Clinical correlates of self-mutilation in a sample of general psychiatric patients. J Nerv Ment Dis. 1999;187:296-301.

18. Bacskai E, Czobor P, Gerevich J. Trait aggression, depression and suicidal behavior in drug dependent patients with and without ADHD symptoms. Psychiatry Res. 2012;200:719-23.

19. Carli V, Jovanovic N, Podlesek A, Roy A, Rihmer Z, Maggi S, Marusic D, Cesaro C, Marusic A, Sarchiapone M. The role of impulsivity in selfmutilators, suicide ideators and suicide attempters - a study of 1265 male incarcerated individuals. J Affect Disord. 2010;123:116-22.

20. Cerutti R, Manca M, Presaghi F, Gratz KL. Prevalence and clinical correlates of deliberate self-harm among a community sample of Italian adolescents. J Adolesc. 2011;34:337-47.

21. Crowell SE, Beauchaine TP, Hsiao RC, Vasilev CA, Yaptangco M, Linehan MM, McCauley E. Differentiating adolescent self-injury from adolescent depression: possible implications for borderline personality development. J Abnorm Child Psychol. 2012;40:45-57.

22. Darke S, Torok M. Childhood physical abuse, non-suicidal self-harm and attempted suicide amongst regular injecting drug users. Drug Alcohol Depend. 2013;133:420-6.

23. Evren C, Dalbudak E, Evren B, Can Y, Umut G. The severity of attention deficit hyperactivity symptoms and its relationship with lifetime substance use and psychological variables among 10th grade students in Istanbul. Compr Psychiatry. 2014;55:1665-70.

24. Feingold D, Nitzan U, Ratzoni G, Lev-Ran S. Clinical Correlates of Alcoho Abuse among Adolescent Psychiatric Inpatients in Israel. Isr J Psychiatry Relat Sci. 2014;51:258-60

25. Fulwiler C, Forbes C, Santangelo SL, Folstein M. Self-mutilation and suicide attempt: distinguishing features in prisoners. J Am Acad Psychiatry Law. 1997:25:69-77.

26. Garcia-Nieto R, Blasco-Fontecilla H, de Leon-Martinez V, Baca-Garcia E. Clinical Features Associated with Suicide Attempts versus Suicide Gestures in an Inpatient Sample. Arch Suicide Res. 2014;18:419-31.

27. Gatta M, Dal Santo F, Rago A, Spoto A, Battistella PA. Alexithymia, impulsiveness, and psychopathology in nonsuicidal self-injured adolescents. Neuropsychiatr Dis Treat. 2016;12:2307-17.

28. Guendelman MD, Owens EB, Galan C, Gard A, Hinshaw SP. Early-adult correlates of maltreatment in girls with attention-deficit/hyperactivity disorder: Increased risk for internalizing symptoms and suicidality. Dev Psychopathol. 2016:28:1-14.

29. Guertin T, Lloyd-Richardson E, Spirito A, Donaldson D, Boergers J. Selfmutilative behavior in adolescents who attempt suicide by overdose. J Am Acad Child Adolesc Psychiatry. 2001:40:1062-9.

30. Hinshaw SP, Owens EB, Zalecki C, Huggins SP, Montenegro-Nevado AJ, Schrodek E, Swanson EN. Prospective follow-up of girls with attention-deficit/hyperactivity disorder into early adulthood: continuing impairment includes elevated risk for suicide attempts and self-injury. J Consult Clin Psychol. 2012;80:1041-51.

31. Hurtig T, Taanila A, Moilanen I, Nordstrom T, Ebeling H. Suicidal and self-harm behaviour associated with adolescent attention deficit hyperactivity disorder-a study in the Northern Finland Birth Cohort 1986. Nord J Psychiatry. 2012;66:320-8.

32. Ilomaki E, Rasanen P, Villo K, Hakko H. Suicidal behavior among adolescents with conduct disorder-the role of alcohol dependence. Psychiatry Res. 2007;150:305-11.

33. Izutsu T, Shimotsu S, Matsumoto T, Okada T, Kikuchi A, Kojimoto M, Noguchi H, Yoshikawa K. Deliberate self-harm and childhood hyperactivity in junior high school students. Eur Child Adolesc Psychiatry. 2006;15:172-6.

34. Jacobson CM, Muehlenkamp JJ, Miller AL, Turner JB. Psychiatric impairment among adolescents engaging in different types of deliberate self-harm. J Clin Child Adolesc Psychol. 2008;37:363-75. 
35. Jenkins AL, McCloskey MS, Kulper D, Berman ME, Coccaro EF. Self-harm behavior among individuals with intermittent explosive disorder and personality disorders. J Psychiatr Res. 2015;60:125-31.

36. Keenan K, Hipwell AE, Stepp SD, Wroblewski K. Testing an equifinality mode of nonsuicidal self-injury among early adolescent girls. Dev Psychopathol. 2014;26:851-62.

37. Kirkcaldy BD, Brown J, Siefen RG. Disruptive behavioural disorders, self harm and suicidal ideation among German adolescents in psychiatric care. Int J Adolesc Med Health. 2006;18:597-614.

38. McCloskey MS, Ben-Zeev D, Lee R, Coccaro EF. Prevalence of suicidal and self-injurious behavior among subjects with intermittent explosive disorder. Psychiatry Res. 2008;158:248-50.

39. Meza Jl, Owens EB, Hinshaw SP. Response Inhibition, Peer Preference and Victimization, and Self-Harm: Longitudinal Associations in Young Adult Women with and without ADHD. J Abnorm Child Psychol. 2015;

40. Nock MK, Joiner TE Jr, Gordon KH, Lloyd-Richardson E, Prinstein MJ. Nonsuicidal self-injury among adolescents: diagnostic correlates and relation to suicide attempts. Psychiatry Res. 2006;144:65-72.

41. Preyde M, Watkins H, Csuzdi N, Carter J, Lazure K, White S, Penney R, Ashbourne G, Cameron G, Frensch K. Non-suicidal self-injury and suicidal behaviour in children and adolescents accessing residential or intensive home-based mental health services. J Can Acad Child Adolesc Psychiatry. 2012;21:270-81.

42. Semiz UB, Basoglu C, Oner O, Munir KM, Ates A, Algul A, Ebrinc S, Cetin M. Effects of diagnostic comorbidity and dimensional symptoms of attentiondeficit-hyperactivity disorder in men with antisocial personality disorder. Austr N Z J Psychiatry. 2008:42:405-13.

43. Swanson EN, Owens EB, Hinshaw SP. Pathways to self-harmful behaviors in young women with and without ADHD: a longitudinal examination of mediating factors. J Child Psychol Psychiatry Allied Discip. 2014;55:505-15.

44. Taylor MR, Boden JM, Rucklidge JJ. The relationship between ADHD symptomatology and self-harm, suicidal ideation, and suicidal behaviours in adults: a pilot study. Atten Deficit Hyperactivity Disord. 2014;6:303-12.

45. You J, Leung F, Fu K, Lai CM. The prevalence of nonsuicidal self-injury and different subgroups of self-injurers in Chinese adolescents. Arch Suicide Res. 2011;15:75-86.

46. Nock MK, Holmberg EB, Photos VI, Michel BD. Self-Injurious Thoughts and Behaviors Interview: development, reliability, and validity in an adolescent sample. Psychol Assess. 2007;19:309-17.

47. Comtois K, Linehan MM. Lifetime Parasuicide Count: Description and Psychometrics. Paper presented at the 32nd annual meeting of the American Association of Suicidology, Houston, TX. 1999.

48. Claes L, Vandereycken W, Vertommen H. Self-injurious behaviors in eatingdisordered patients. Eat Behav. 2001;2:263-72.

49. Gratz KL. Measurement of Deliberate Self-Harm: Preliminary Data on the Deliberate Self-Harm Inventory. J Psychopathol Behav Assess. 2001;23:253-63.

50. Lloyd EE, Kelley ML, Hope T. Self-mutilation in a community sample of adolescents: descriptive characteristics and provisional prevalence rates. New Orleans: Poster presented at the Annual Meeting of the Society for Behavioral Medicine; 1997.

51. Vanderlinden J, Vandereycken W. Trauma, dissociation, and impulse decontrol in eating disorders. Philadelphia, PA: Brunner/Mazel; 1997.

52. Kapur N, Cooper J, O'Connor RC, Hawton K. Non-suicidal self-injury v. attempted suicide: new diagnosis or false dichotomy? Br J Psychiatry. 2013;202:326-8

53. Nock MK. Self-injury. Annu Rev Clin Psychol. 2010;6:339-63.

54. Hamza CA, Willoughby T, Heffer T. Impulsivity and nonsuicidal self-injury: A review and meta-analysis. Clin Psychol Rev. 2015;38:13-24.

55. Lockwood J, Daley D, Townsend E, Sayal K. Impulsivity and self-harm in adolescence: a systematic review. Eur Child Adolesc Psychiatry. 2017;26:387-402.

56. Grandclerc S, De Labrouhe D, Spodenkiewicz M, Lachal J, Moro MR. Relations between Nonsuicidal Self-Injury and Suicidal Behavior in Adolescence: A Systematic Review. PLoS One. 2016;11:e0153760.

\section{Submit your next manuscript to BioMed Central and we will help you at every step:}

- We accept pre-submission inquiries

- Our selector tool helps you to find the most relevant journal

- We provide round the clock customer support

- Convenient online submission

- Thorough peer review

- Inclusion in PubMed and all major indexing services

- Maximum visibility for your research

Submit your manuscript at www.biomedcentral.com/submit
O) Biomed Central 